\title{
EUPHORBIA TIRUCALLI L.: AVALIAÇÃO DA ATIVIDADE BIOLÓGICA DE EXTRATOS OBTIDOS POR AGITAÇÃO CONTÍNUA OU ULTRASSOM
}

\author{
PAULO HENRIQUE DE HOLANDA VELOSO JÚNIOR* \\ ALESSANDRO DE LIMA** \\ JURANDY DO NASCIMENTO SILVA*** \\ JHONES DO NASCIMENTO DIAS**** \\ RONALDO ZUCATELLI MENDONÇA***** \\ ANA CAROLINA FONSECA LINDOSO MELO****** \\ REGINALDO ALMEIDA DA TRINDADE ${ }^{* * * * * * *}$
}

\begin{abstract}
Extratos de plantas possuem compostos bioativos com múltiplas possibilidades de aplicação na indústria biotecnológica, farmacêutica e alimentícia. Este trabalho avaliou extratos obtidos da espécie Euphorbia tirucalli L. cultivada no litoral do estado do Piauí. Foram quantificados compostos fenólicos totais e avaliadas pelas metodologias do $\mathrm{DPPH} \mathrm{e}^{\bullet} \mathrm{e} \mathrm{ABTS}^{\bullet+}$ as atividades antioxidantes presente nos extratos acetônicos ou hidrometanólicos obtidos por agitação contínua ou ultrassom. A viabilidade celular foi morfológica e metabolicamente avaliada em células $L L C-M K_{2}$ pelo ensaio MTT e a atividade antiparasitária pelo ensaio de infectividade celular por tripomastigotas de Trypanosoma cruzi. Os compostos fenólicos totais variaram de 0,65 a 13,78 $\mathrm{mgGAE} / \mathrm{g}$, e diferiram estatisticamente $(p<0,05)$ entre extratos preparados com diferentes solventes (hidrometanólico>acetônico) e diferentes métodos de extração (ultrassom>agitação contínua). As extrações mostraramse mais eficientes para amostras secas tanto sob agitação contínua $(12,48 \pm 0,34)$ como por ultrassom $(13,78 \pm 0,14)$. A atividade antioxidante, avaliada por $\mathrm{DPPH}^{\bullet}$ e ABTS ${ }^{\bullet+}$, variou de acordo com os teores dos compostos fenólicos. A concentração inibidora da viabilidade celular variou de 0,2 a $2 \mathrm{mg} / \mathrm{mL}$ nos extratos, entretanto, o ácido ferúlico isolado mostrou-se inerte até $2 \mathrm{mg} / \mathrm{mL}$. Não foi observada inibição da infectividade celular pelos extratos e ou pelo ácido ferúlico isolado. Portanto, extratos hidrometanólicos de Euphorbia tirucalli L. preparados com amostras secas, submetidos à ultrassonicação, apresentaram maiores quantidades de compostos fenólicos e uma considerável atividade antioxidante.
\end{abstract}

PALAVRAS CHAVE: ATIVIDADE ANTIOXIDANTE, ATIVIDADE ANTIPARASITÁRIA, EUPHORBIA TIRUCALLI L., ÁCIDO FERÚLICO.

* Biomédico e Mestre em Biotecnologia, Universidade Federal do Piauí (UFPI), Parnaíba-PI, (e-mail: phhvjunior@gmail.com).

** Doutor em Ciências dos Alimentos, Professor Associado do Departamento de Alimentos, Instituto Federal de Educação, Ciência e Tecnologia do Piauí (IFPI), Teresina-PI, (e-mail: alessandro@ifpi.edu.br).

*** Doutorando em Biotecnologia, Rede Nordeste de Biotecnologia (RENORBIO), Teresina-PI, (e-mail: jurandy@ifpi.edu.br).

**** Biomédico e Mestre em Biotecnologia, Universidade Federal do Piauí (UFPI), Parnaíba-PI, (e-mail: jhonesnd@gmail.com).

***** Doutor em Ciências Biológicas, Pesquisador Cientifico, Instituto Butantan (IB), São Paulo-SP, (e-mail: ronaldo. mendonca@butantan.gov.br).

****** Doutora em Ciências Veterinárias, Professor Adjunto no Departamento de Patologia e Medicina Legal da Faculdade de Medicina, Universidade Federal do Ceará (UFC), Fortaleza-CE, (e-mail: acflmelo@gmail.com).

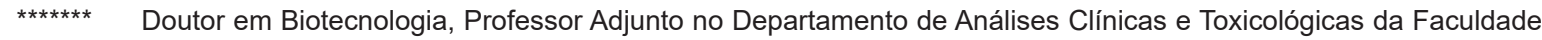
de Farmácia, Universidade Federal do Rio de Janeiro (UFRJ), Rio de Janeiro-RJ, (e-mail: rtrindade@pharma.ufrj.br). \# Autor correspondente. 


\section{INTRODUÇÃO}

Euphorbia tirucalli L. é uma planta de origem africana, pertencente à família Euphorbiaceae. No Brasil, esta planta é predominantemente cultivada na região norte e nordeste, onde é popularmente conhecida como avelóz, cachorro-pelado, árvore-do-lápis, cega-olho ou espinho-italiano. É uma planta utilizada na medicina tradicional popular para tratamento de doenças como sífilis, asma, reumatismo, câncer e AIDS (DUTRA et al., 2011; BANI et al., 2007; MELO et al., 2011; ABREU et al., 2014).

Os efeitos benéficos observados com o uso da Euphorbia tirucalli L. podem ser atribuídos em parte aos seus compostos fenólicos constituintes do seu metabolismo secundário. Estudos indicam que estes compostos, quando consumidos em uma dieta regular, pode reduzir significativamente $o$ desenvolvimento de doenças relacionadas ao estresse oxidativo, visto que estas moléculas agem como neutralizadores de radicais livres (WANG et al., 2011; WOOTTON-BEARD e RYAN, 2011). Dentre os vários compostos fenólicos presentes na Euphorbia tirucalli L., o ácido ferúlico tem sido identificado como o mais predominante (DE ARAÚJO et al., 2014).

O ácido ferúlico é uma molécula quimicamente descrita como ácido 4-hidroxi-3-metoxicinâmico, que é formada a partir do metabolismo dos aminoácidos fenilalanina e tirosina. É extremamente abundante no reino vegetal, sendo encontrado em folhas e sementes de muitas plantas (GRAF, 1992). A figura 1 mostra a estrutura química do ácido ferúlico.

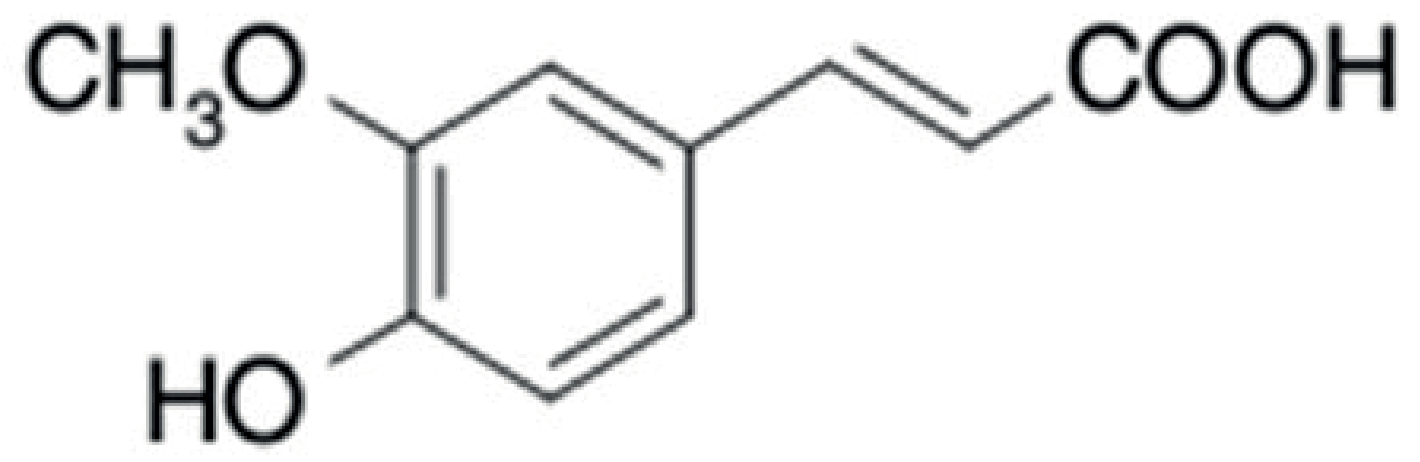

FIGURA 1. ESTRUTURA QUÍMICA DO ÁCIDO FERÚLICO (BALASUNDRAM ET AL., 2006).

Na literatura há a descrição de algumas aplicações farmacêuticas do ácido ferúlico que incluem: atividade antioxidante na formulação tópica de protetores dos raios ultravioletas (MURRAY et al., 2008), atividade de inibição do crescimento de Listeria monocytogenes, um dos agentes etiológicos da meningite bacteriana (TAKAHASHI et al., 2013), atividade de redução na progressão do câncer de mama (BASKARAN et al., 2010), redução do aparecimento de doenças cardiovasculares (ASWAR et al., 2013) e neurodegenerativas (SULTANA, 2012). Entretanto, há poucos trabalhos que descrevam a capacidade do ácido ferúlico em atuar como antiparasitário, especialmente, sobre protozoários.

O presente estudo teve como objetivo quantificar os compostos fenólicos presentes em extratos acetônicos ou hidrometanólicos obtidos por ultrassom ou agitação contínua das amostras da parte aérea da Euphorbia tirucalli L. coletadas no litoral do estado do Piauí, seguida da avaliação da atividade antioxidante pelos métodos de DPPH' e ABTS ${ }^{+}$. Além disso, também foi verificada a atividade antiparasitária por meio da inibição da infectividade celular por tripomastigotas de Trypanosoma cruzi em culturas de células mamíferas. Estas células também foram utilizadas na avaliação da influência dos extratos e do ácido ferúlico isolado sobre a viabilidade celular. 


\section{MATERIAL E MÉTODOS}

\subsection{REAGENTES}

Os compostos ácido gálico, ácido ferúlico, radical 2,2-difenil-1-picril-hidrazil (DPPH•), radical (2,2'-azinobis (3-etilbenzotiazolina-6-ácido sulfônico) (ABTS ${ }^{*+}$ ), persulfato de potássio, Trolox® 6-hydroxi-2,5,7,8-tetrametilchromon-2-ácidocarboxílico, MTT - [3-(4,5-dimetiltiazol-2il)2,5-difenil brometo de tetrazolium foram obtidos da Sigma-Aldrich Chemical® (Milwaukee/USA). Dimetilsulfóxido (DMSO), reagente Folin e o carbonato de sódio $\left(\mathrm{NaCO}_{3}\right)$ foram da Merck®. Os demais solventes e reagentes foram de grau analítico.

\subsection{COLETA, IDENTIFICAÇÃO E MANUSEIO DA PLANTA}

As amostras da parte aérea da Euphorbia tirucalli L. foram coletadas no município de Luís Correia, situado no litoral do estado do Piauí, Brasil, a $02^{\circ} 52^{\prime} 45^{\prime \prime}$ de latitude sul e $41^{\circ} 40^{\prime} 01^{\prime \prime}$ de longitude oeste, entre agosto e setembro de 2014. Segundo dados meteorológicos para o referido período, a temperatura mínima era de $25^{\circ} \mathrm{C}$ e a máxima de $34^{\circ} \mathrm{C}$, com baixa precipitação de chuva (2-5 mm). A planta foi formalmente identificada pela professora Ivanilza Moreira de Andrade, $\mathrm{PhD}$, do Laboratório de Taxonomia da Universidade Federal do Piauí, campus de Parnaíba. O depósito da excicata foi realizado no Herbário Delta do Parnaíba da Universidade Federal do Piauí, campus Ministro Reis Velloso sob protocolo $\mathrm{n}^{\circ} 1192$.

Inicialmente, as partes selecionadas da planta foram lavadas com água destilada, trituradas em moinho analítico e divididas em dois grupos. O primeiro grupo foi desidratado em estufa fechada com circulação de ar a $110^{\circ} \mathrm{C}$ por 9 horas, e denominado amostra seca. $\mathrm{O}$ segundo grupo foi mantido em temperatura ambiente, e denominado amostra fresca. Os extratos foram preparados e analisados no Laboratório de Análises de Alimentos do Instituto Federal do Piauí (IFPI).

\subsection{EXTRAÇÃO POR AGITAÇÃO CONTÍNUA}

A extração convencional foi realizada sob agitação contínua. Foram adicionados $200 \mathrm{~mL}$ dos solventes acetona ou metanol/água $(80: 20 \mathrm{v} / \mathrm{v})$ a $20 \mathrm{~g}$ de amostra fresca ou $10 \mathrm{~g}$ de amostra seca de Euphorbia tirucalli L. segundo a metodologia de UPADHYAY et al. (2010) e OLIVEIRA et al. (2011) com adaptações. A mistura foi submetida à agitação controlada de $10 \mathrm{rpm}$ por 1 hora em mesa agitadora sem aquecimento. Posteriormente, a mistura foi filtrada sob vácuo em papel filtro com poros de 20-25 $\mu \mathrm{m}$ para retenção de partículas e armazenada em frasco âmbar.

\subsection{EXTRAÇÃO POR ULTRASSOM}

$\mathrm{Na}$ extração por ultrassom, substituiu-se a etapa de agitação pela etapa de banho ultrassônico em equipamento Elmasonic $\mathrm{P} 60 \mathrm{H}$ por 1 hora a 37 watts, de acordo com a metodologia descrita por SOUZA, 2014.

Ao todo, oito extratos foram obtidos e nomeados como: E1 (Extrato acetônico seco ultrassom); E2 (Extrato hidrometanólico seco - ultrassom); E3 (Extrato acetônico fresco - ultrassom); E4 (Extrato hidrometanólico fresco - ultrassom); E5 (Extrato acetônico seco - agitação contínua); E6 (Extrato hidrometanólico seco - agitação contínua); E7 (Extrato acetônico fresco - agitação contínua); E8 (Extrato hidrometanólico fresco - agitação contínua).

\subsection{QUANTIFICAÇÃO DOS FENÓLICOS TOTAIS}

A quantificação dos compostos fenólicos foi realizada pelo método de Folin utilizando o reagente Folin-Denis segundo metodologia de SWAIN e HILLS (1959), com adaptações de LIMA 
(2008). Sucintamente, $0,5 \mathrm{~mL}$ do extrato foram adicionados a $8 \mathrm{~mL}$ de água destilada, seguido de $0,5 \mathrm{~mL}$ do reagente Folin-Denis. Procedeu-se a agitação em vortex por 3 minutos, e acrescentou-se $1 \mathrm{~mL}$ de solução saturada de $\mathrm{NaCO}_{3}$. A reação foi mantida por 1 hora protegida da luz. Ao término deste tempo, leituras espectrofotométricas foram realizadas a $\lambda 720 \mathrm{~nm}$ contra um branco contendo todos os reagentes exceto os extratos. Uma curva padrão foi preparada utilizando concentrações de ácido gálico variando de 50 a $750 \mathrm{mg} / \mathrm{mL}$. Os valores dos compostos fenólicos foram expressos em equivalentes de ácido gálico/g de amostra (mgGAE/g).

\subsection{AVALIAÇÃO DA ATIVIDADE ANTIOXIDANTE}

\subsubsection{Metodologia do Sequestro do Radical DPPH•}

O ensaio colorimétrico de sequestro do radical 2,2 difenil-1-picril-hidrazil (DPPH•) foi realizado de acordo com o protocolo descrito por BLOIS (1958) e adaptado por BRAND-WILLIANS et al. (1995). Resumidamente, adicionaram-se $0,5 \mathrm{~mL}$ dos diferentes extratos a $1,5 \mathrm{~mL}$ de solução etanólica de $\mathrm{DPPH}^{\bullet}\left(6 \times 10^{-5} \mathrm{M}\right)$. As misturas foram agitadas e após 30 minutos a absorbância foi medida a $\lambda 517 \mathrm{~nm}$. As reações foram acompanhadas de controles consistindo somente do radical $\mathrm{DPPH} \bullet$ em solução etanólica.

A atividade antioxidante, expressa em percentagem de atividade sequestradora de radicais $\mathrm{DPPH}^{\bullet}$, foi calculada de acordo com a equação 1 :

\section{\% proteção da oxidação: (Abs amostra - Abs controle) $\times 100$ Abs controle}

Aatividade antioxidante pelo sequestro do radical DPPH• também foi expressa em relação ao antioxidante sintético Trolox $®$, análogo à Vitamina E. Soluções padrão de Trolox® foram preparadas nas concentrações de 2 a $125 \mu \mathrm{M} / \mathrm{mL}$. Os resultados foram expressos em $\mu \mathrm{M}$ de Trolox® por grama de amostra (TEAC - Trolox Equivalent Antioxidant Capacity). Todos os testes foram realizados em triplicatas, sendo calculado o valor médio e o desvio padrão.

\subsubsection{Metodologia de Neutralização do Radial ABTS**}

O ensaio de $\mathrm{ABTS}^{\bullet+}$ foi baseado no método descrito por RE et al. (1999). Sucintamente, $7 \mathrm{mM}$ de ABTS foram misturados a $140 \mathrm{mM}$ de persulfato de potássio em uma solução aquosa. A mistura foi incubada à temperatura ambiente durante $12 \mathrm{~h}$, permitindo a formação do cátion radical ABTS ${ }^{++}$. A solução resultante foi dissolvida em etanol até obter-se uma absorbância de 0,70 $\pm 0,02$ à $\lambda 734 \mathrm{~nm}$. Em seguida, foram adicionados $40 \mu \mathrm{L}$ dos extratos a $1.960 \mu \mathrm{L}$ da solução contendo o radical $A B T S{ }^{\bullet+}$. As absorbâncias foram determinadas em espectrofotômetro a $\lambda 734 \mathrm{~nm}$ após 30 minutos de reação. As reações foram realizadas em triplicatas e acompanhadas de um controle sem extratos. $O$ antioxidante padrão utilizado foi o Trolox ${ }^{\circledR}$ nas concentrações de 50 a $800 \mu \mathrm{M} /$ $\mathrm{mL}$. Os resultados expressos em $\mu \mathrm{M}$ de Trolox ${ }^{\circledR}$ por grama de amostra (TEAC - Trolox Equivalent Antioxidant Capacity). Todos os testes foram realizados em triplicatas, sendo calculado o valor médio e o desvio padrão.

\subsection{ENSAIOS DE VIABILIDADE CELULAR EM CÉLULAS LLC-MK ${ }_{2}$}

A viabilidade celular foi investigada pela adição dos extratos da Euphorbia tirucalli $L$. e o ácido ferúlico isolado à cultivos de células LLC-MK ${ }_{2}$ (obtidas de rim de macaco Rhesus - Macaca mulatta), seguida de análise morfológica das células sob microscopia óptica e pelo ensaio colorimétrico do MTT (sal de tetrazolium [3-(4,5-dimetiltiazol-2-il)2,5-difenil brometo de tetrazolium]). Células metabolicamente viáveis reduzem o composto MTT à formazan. Na presença de um composto teste, a viabilidade é verificada pela diminuição desta açaõa redutora, indicando ações citotóxicas do composto (HEINEN et al., 2014). 
Para a análise morfológica, as células LLC-MK ${ }_{2}$ foram obtidas por repiques sucessivos em meio Leibovitz, suplementado com $10 \%$ de soro fetal bovino e $1 \%$ de antibióticos, sendo incubadas a $37^{\circ} \mathrm{C}$ por $24 \mathrm{~h}$, em câmara de $\mathrm{CO}_{2}$ a $5 \%$ Em seguida, a células foram transferidas para placas de 96 poços na concentração de $0,5 \times 10^{5}$ células/poço. Após $24 \mathrm{~h}$ de incubação nas condições acima, quando os tapetes celulares tornaram-se confluentes, adicionaram-se em cada poço $100 \mu \mathrm{L}$ do meio Leibovitz contendo os diferentes extratos ou o ácido ferúlico isolado. As concentrações utilizadas variaram de 0,05 a $9 \mathrm{mg} / \mathrm{mL}$ em base seca. $O$ controle negativo (sem ação citotóxica) foi preparado pela adição de $100 \mu \mathrm{L}$ do meio Leibovitz nos respectivos poços. O controle positivo (com ação citotóxica) foi preparado pela adição de DMSO. As placas foram incubadas por 24 horas. Em seguida, o meio foi descartado e as células foram coradas com cristal violeta, seguida da análise morfológica sob microscopia de luz.

Para a análise pelo teste do MTT, as placas contendo as células previamente incubadas com os extratos ou o ácido ferúlico isolado foram lavadas duas vezes com PBS estéril à temperatura de $37^{\circ} \mathrm{C}$, seguidas da adição de $100 \mu \mathrm{L}$ de solução de MTT $(0,5 \mathrm{mg} / \mathrm{mL}$ em meio Leibovitz), e incubadas a $37^{\circ} \mathrm{C}$ por $2 \mathrm{~h}$. Após incubação, o meio contendo o MTT foi removido e $100 \mu \mathrm{L}$ de DMSO foram adicionados para solubilizar o formazan e agitadas por 5 minutos em temperatura ambiente. Leituras espectrofotométricas foram obtidas a $\lambda 540 \mathrm{~nm}$ em uma leitora de microplaca. A viabilidade celular foi determinada comparando as densidades óticas dos cultivos celulares controles com os cultivos testes.

\subsection{AVALIAÇÃO DA ATIVIDADE ANTIPARASITÁRIA}

Células $L L C-\mathrm{MK}_{2}$ mantidas em meio DMEM contendo $10 \%$ de soro fetal bovino foram utilizadas nos ensaios de infectividade por tripomastigotas de Trypanosoma cruzi. Placa de 24 poços foram plaqueadas na concentração de $10^{4}$ células $\left(L L C-M K_{2}\right)$ em $1 \mathrm{~mL}$ de meio. Após $24 \mathrm{~h}$, estas células foram tratadas por $1 \mathrm{~h}$ com as respectivas amostras testes: ácido ferúlico (1\%), extrato E2 (0,5\%), E4 (0,5\%), E6 (0,5\%) e E8 (1\%).

Em seguida, as células foram infectadas com $5 \times 10^{5}$ tripomastigotas de Trypanosoma cruzi. Células não tratadas serviram de controle positivo para infecção. Após 24 h, o meio foi retirado, as células foram lavadas com PBS, fixadas com paraformaldeído por 10 minutos, permeabilizadas com PBS/TRITON X-100 0,1\% por 5 minutos e, finalmente, foram coradas por DAPI por 1 hora na diluição de 1:10.000 em PBS. Sob microscopia de fluorescência, foram obtidas as imagens do controle positivo e das células tratadas, e contaram-se as células infectadas.

\subsection{ANÁLISE ESTATÍSTICA}

Todas as análises experimentais foram realizadas em triplicatas. Os resultados foram expressos em média e desvio-padrão (SD). A avaliação das diferenças nos valores foi realizada pela análise de variância (ANOVA). Se detectadas diferenças estatisticamente significativas $(p<0,05)$, o pós-teste de Tukey foi aplicado. Para comparação da eficiência dos dois métodos de extração (agitação contínua e ultrassom) foi aplicado o teste $t$ de student, considerando a diferença estatisticamente significativa quando o valor de $p<0,05$.

\section{RESULTADOS E DISCUSSÃO}

\subsection{EFICIÊNCIA DA EXTRAÇÃO DOS FENÓLICOS TOTAIS PELOS MÉTODOS DE ULTRASSOM E AGITAÇÃO CONTÍNUA}

A Tabela 1 apresenta o teor de compostos fenólicos presente nos extratos acetônico e hidrometanólico obtidos a partir das amostras seca e fresca da parte aérea da Euphorbia tirucalli 
L. utilizando ultrassom ou agitação contínua. Os valores indicaram que ambos os solventes, bem como os dois métodos foram eficientes na extração dos compostos fenólicos, cujas concentrações variaram de 0,65 a 13,78 mgGAE/g de amostra. Entretanto, os valores diferiram estatisticamente $(p<0,05)$ tanto em relação às diferentes amostras e solventes utilizados como em relação ao método de extração utilizado. Sucintamente, os extratos hidrometanólicos apresentaram valores superiores aos encontrados nos extratos acetônicos, sendo que a extração realizada a partir da amostra seca foi mais eficiente do que a extração a partir da amostra fresca tanto pelo método de agitação contínua $(12,48 \pm 0,34 \mathrm{mgGAE} / \mathrm{g})$ como por ultrassom $(13,78 \pm 0,14 \mathrm{mgGAE} / \mathrm{g})$.

\section{TABELA 1. FENÓLICOS TOTAIS DOS EXTRATOS SECO E FRESCO ACETÔNICO E HIDROMETANÓLICO DA PARTE AÉREA DA EUPHORBIA TIRUCALLI L. OBTIDOS PELOS MÉTODOS DE ULTRASSOM E AGITAÇÃO CONTÍNUA. OS VALORES FORAM EXPRESSOS EM EQUIVALENTES DE ÁCIDO GÁLICO (MG GAE/1 G AMOSTRA)*.}

\begin{tabular}{|c|c|c|}
\hline Amostras & Ultrassom & Agitação contínua \\
\hline E. Seco Acetônico & $1,08 \pm 0,09^{\mathrm{Aa}}$ & $0,65 \pm 0,06^{A b}$ \\
\hline E. Seco Hidrometanólico & $13,78 \pm 0,14^{\mathrm{Ba}}$ & $12,48 \pm 0,34^{\mathrm{Bb}}$ \\
\hline E. Fresco Acetônico & $4,67 \pm 0,07^{\mathrm{Ca}}$ & $5,12 \pm 0,09^{\mathrm{cb}}$ \\
\hline E. Fresco Hidrometanólico & $6,49 \pm 0,13^{\mathrm{Da}}$ & $5,75 \pm 0,14^{\mathrm{Db}}$ \\
\hline
\end{tabular}

Compostos fenólicos são metabólitos secundários presentes nas plantas que constituem um extenso grupo de fitoquímicos com mais de 8.000 compostos já identificados (MUNIN e EDWARDS-LÉVY, 2011; EBRAHIMI e SCHLUESENER, 2012). Por sua complexidade, variedade e interação com outros componentes das plantas (LI et al., 2009), não há processo único que extraia a totalidade desses fitoquímicos. Neste sentido, a utilização de diferentes solventes mobiliza diferentes compostos baseado em afinidades químicas. Além disso, diferentes processos físicos de extração mostram eficiências variadas. Nos últimos anos, para otimização das extrações, têmse empregado tanto diferentes solventes, como diferentes forças físicas, entre as quais, destacase a extração por ondas ultrassônicas (PORTO et al., 2013; BARRERA-VÁZQUEZ et al., 2014; SOUZA, 2014; TEH \& BIRCH, 2014; CHARPE and RATHOD, 2016; ALTEMINI et al., 2016; HE et al., 2016).

Foi verificado que os extratos hidrometanólicos obtidos a partir das amostras secas forneceram maiores valores de compostos fenólicos totais. Essa maior eficiência de extração também foi encontrada por DE ARAÚJO et al. (2014) que quantificaram compostos fenólicos totais em extratos de E. tirucalli. HOSSAIN et al. (2010) também encontraram resultados similares em extratos obtidos de diferentes ervas por metodologias distintas. Estes autores citam algumas razões para os extratos obtidos de amostras secas fornecerem valores maiores de compostos fenólicos em relação às amostras frescas, que possuem elevada atividade de água. Por exemplo, HOSSAIN et al. (2010) relataram que o processo de secagem torna as células mais frágeis, permitindo que a extração as rompam mais facilmente causando maior liberação dos metabólitos intracelulares, entre estes, os compostos fenólicos. Outras razões também são citadaspara explicar essas diferenças. Primeiramente, a possível ocorrência de degradação enzimática dos compostos fenólicos nas amostras frescas. Sabe-se que as enzimas atuam apenas em ambiente aquoso, o que não aconteceria nas amostras secas. Em segundo, considerando que alguns polifenóis possuem ação 
de defesa nas plantas, o processo de secagem geraria estresse físico nas células, induzindo uma maior produção de polifenois.

No presente trabalho, a extração por ondas ultrassônicas, comparada com a agitação continua, mostrou-se mais eficiente na extração dos compostos fenólicos, exceção para o extrato acetônico de amostra fresca. MA et al. (2008) e MORELLI e PRADO (2012) corroboram esses resultados ao relatarem maior eficiência e menor tempo de extração ao utilizarem ondas ultrassônicas, em comparação com a agitação contínua convencional. Esses autores explicam que as ondas ultrassônicas rompem as paredes celulares presentes na matriz vegetal, aumentando a penetração do solvente e o contato entre as fases soluto/solvente, facilitando a liberação dos fitoquímicos. A eficiência das ondas ultrassônicas em processos de extração também é reportada por outros autores estudando diferentes matrizes vegetais, tais como sementes de uvas (PORTO et al., 2013), folha de Louro (MUÑIZ-MÁRQUEZ et al., 2013) e sementes de canola (TEH \& BIRCH, 2014). CHEMAT et al. (2017) revisaram a utilização de ondas ultrassônicas em extrações e enfatizam além da eficiência, o atendimento dessa metodologia aos critérios mercadológicos e regulatórios de uso de energias sustentáveis.

DE ARAÚJO et al. (2014) investigou o teor de compostos fenólicos da Euphorbia tirucalli L. cultivada no município de Teresina-PI, e encontrou concentrações de compostos fenólicos em extratos secos acetônicos e hidrometanólicos de $30.54 \pm 0.64$ e $27.6 \pm 2.34 \mathrm{mg} \mathrm{GAE} / 100 \mathrm{~g}$, respectivamente. Comparada aos resultados acima, a Euphorbia tirucalli $L$. obtida do litoral piauiense apresentou maiores concentrações de compostos fenólicos. Tais resultados podem ser explicados pelas variações nas condições do solo, tais como oferta de água e sais minerais, pois a restrição desses itens favorece à produção dos polifenóis, além da própria oscilação do clima (VARRICCHIO et al., 2008). Variações dos compostos fenólicos em plantas coletadas em diferentes áreas com condições climáticas diferentes também foram reportadas por MODNICKI e LABDZKA (2009), MALES et al. (2010), GHASEMZADEH e JAAFAR (2013) e ALAM et al. (2014).

Em razão da ausência de estudos relatando o teor dos compostos fenólicos especificamente em Euphorbia tirucalli L., os resultados do presente estudo foram também comparados aos obtidos com outras plantas medicinais. Por exemplo, BASMA et al. (2011) ao avaliarem o extrato metanólico de folhas, flores, raízes e caules da espécie Euphorpia hirta $L$. encontraram valores de compostos fenólicos totais de 206,17 $\pm 1,95 \mathrm{mgGAE} / \mathrm{g}, 117,08 \pm 3.10$ $\mathrm{mgGAE} / \mathrm{g}, 83,15 \pm 1,19 \mathrm{mgGAE} / \mathrm{g}$ e $65.70 \pm 1,72 \mathrm{mg}$ GAE/g, respectivamente. Em outro estudo, DZOYEM e ELOFF (2015) avaliaram o teor de compostos fenólicos em extratos acetônicos das folhas de doze plantas tradicionalmente utilizadas para aliviar a dor e inflamação na África do Sul e encontraram valores entre $428 \pm 88$ e $100 \pm 4 \mathrm{mgGAE} / \mathrm{g}$. Essas variações reforçam a ampla variabilidade desses compostos bioativos nas diferentes plantas, corroborando que as condições de cultivo exercem influência em suas produções.

\subsection{AVALIAÇÃO DA ATIVIDADE ANTIOXIDANTE: MÉTODO DPPH•}

As figuras $2 \mathrm{~A}$ a $2 \mathrm{D}$ mostram a porcentagem de inibição dos efeitos oxidantes pelos diferentes extratos segundo o método do $\mathrm{DPPH}^{\bullet}$. Não houve diferença estatística entre os métodos de extração, porém houve em relação aos diferentes solventes e tipos de amostras. Com exceção dos extratos acetônicos de amostras secas (E1 e E5), todos os demais extratos mostraram-se eficientes em inibir a oxidação, com percentual de proteção acima de $80 \%$. Entre estas amostras (E1 e E5), o método de extração utilizado não aumentou a presença de compostos com atividade antioxidante, por outro lado, o tipo de solvente foi um fator com forte influência. A utilização de solvente hidrometanólico sobre amostra seca mostrou ser mais eficiente em extrair maiores quantidades de compostos bioativos capazes de inibir a oxidação no sistema testado (DPPH) tanto no método da agitação contínua como sob ultrassom. Para amostras frescas, a proteção contra oxidação foi similar, independentemente do solvente ou método de extração utilizado. 
Estudos com diferentes espécies de Euphorbia sp têm ratificado as atividades antioxidantes presentes em extratos obtidos com diferentes solventes orgânicos, principalmente o metanol. Por exemplo, BEN MOHAMED MAOULAININE et al. (2012) avaliaram extratos etanólicos das folhas de E. helioscopia e obtiveram valores de proteção contra oxidação acima de $80 \%$ quando as concentrações dos sólidos nos extratos foram maiores que $200 \mu \mathrm{g} / \mathrm{mL}$. Outro estudo realizado por LAHLOU et al. (2014) que avaliou a atividade antioxidante da E. echinus, reportou que extratos metanólicos possuem maior capacidade antioxidante expressa em menores valores de $I_{50}(21,9)$ quando comparados aos extratos aquosos $\left(\mathrm{IC}_{50} 28,6\right)$. Nesse mesmo trabalho, os referidos autores incluíram outra variável que foi a extração metanólica a quente em sistema Soxhlet®, e encontraram atividades antixodantes ainda maiores, expressas por uma $\mathrm{IC}_{50}$ de 4,56 , valor muito próximo à vitamina $\mathrm{C}$ que apresentou $\mathrm{IC}_{50}$ de 3,6.

De uma forma geral, extratos aquosos de Euphorbia sp têm demonstrado menor capacidade antioxidante, conforme resultados reportados por WACZUK et al. (2015) cujo extrato aquoso de $E$. tirucalli mostrou uma porcentagem de proteção antioxidante de aproxidamente $20 \%$ em comparação com um antioxidante controle (ácido ascórbico) mesmo testado na maior concentração de $200 \mu \mathrm{g} /$ $\mathrm{mL}$. Reduzidas atividades antioxidantes também foram reportadas por MUNRO et al. (2015) ao avaliaram extratos aquosos em comparação com extratos metanólicos de E. tirucalli. Esses autores relataram uma proteção antioxidante de aproxidamente $30 \%$ ao utilizarem extratos aquosos, mesmo contendo uma alta concentração de sólidos $(800 \mu \mathrm{g} / \mathrm{mL})$, enquanto os extratos metanólicos mostraram proteções maiores de $45 \%$ e $65 \%$ em concentrações de sólidos de $100 \mu \mathrm{g} / \mathrm{mL}$ e 800 $\mu \mathrm{g} / \mathrm{mL}$, respectivamente. BASMA et al. (2011) reportaram também uma alta proteção antioxidante, aproximadamente $76 \%$, ao avaliarem extratos metanólicos de $E$. hirta na concentração de sólido de 1 $\mathrm{mg} / \mathrm{mL}$. Por outro lado, NASCIMENTO et al. (2013) encontraram resultados diferentes ao avaliarem a ação antioxidante por DPPH de extratos aquosos e metanólicos preparados de Plukenetia volubilis Linneo, uma planta também da família Euphorbiaceae. Esses autores relataram que o extrato aquoso mostrou maior ação antioxidante do que o extrato metanólico, aproximadamente $90 \% \mathrm{e}$ $80 \%$, respectivamente. Ainda que a diferença de porcentagem de proteção tenha sido pequena, ela foi estatisticamente significativa, e sendo assim, trata-se de um resultado interessante do ponto de vista da produção de extratos.

As figuras 3A a 3D mostram a ação antioxidante dos diferentes extratos segundo o método do $\mathrm{DPPH} \bullet$ em comparação ao antioxidante sintético padrão Trolox®. Observou-se que os extratos hidrometanólicos secos obtidos tanto por ultrassom como por agitação contínua foram os que apresentaram maior atividade antioxidante, com valores de 96,84 $\mu \mathrm{M}$ e 94,88 $\mu \mathrm{M}$ equivalentes de Trolox/g de amostra, respectivamente. Não houve diferença estatística entre os métodos de extração, porém houve em relação aos diferentes solventes e amostras. Para as amostras frescas, a atividade comparada ao Trolox® foi discreta e não mostrou estar sob influência do método de extração ou do tipo de solvente utilizado.

Em termos metodológicos, o DPPH•é um método colorimétrico empregado rotineiramente na avaliação de potenciais agentes antioxidantes na eliminação de radicais livres (CHENG et al., 2006). O princípio da técnica baseia-se na medição espectrométrica a $517 \mathrm{~nm}$ da concentração do radical que varia graças a uma reação com algum antioxidante (MILARDOVIC et al., 2006; DAWIDOWICZ et al., 2012). O radical livre DPPH•é estável e possui um elétron desemparelhado na última camada de valência do átomo como um todo (EKLUND et al., 2005; SHARMA e BHAT, 2009). Esse elétron desemparelhado é o responsável pela cor violeta da solução (MOLYNEUX, 2004). 
A

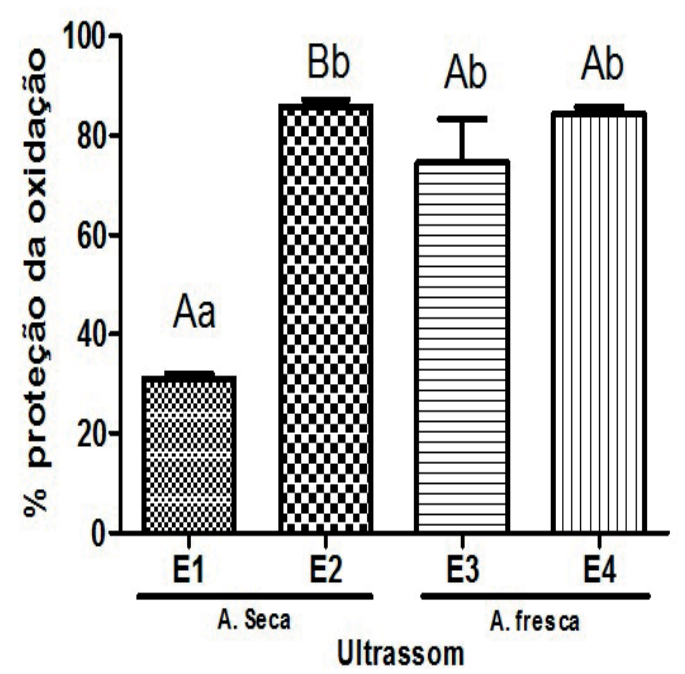

C

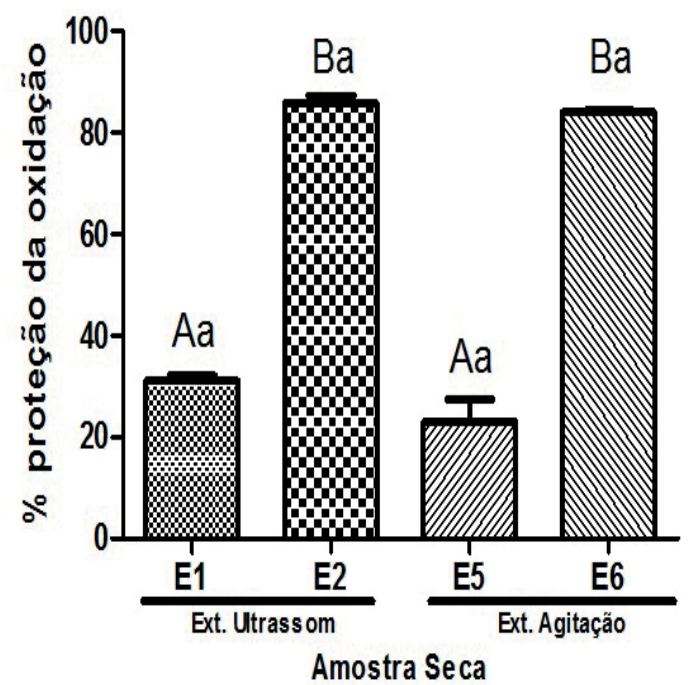

B

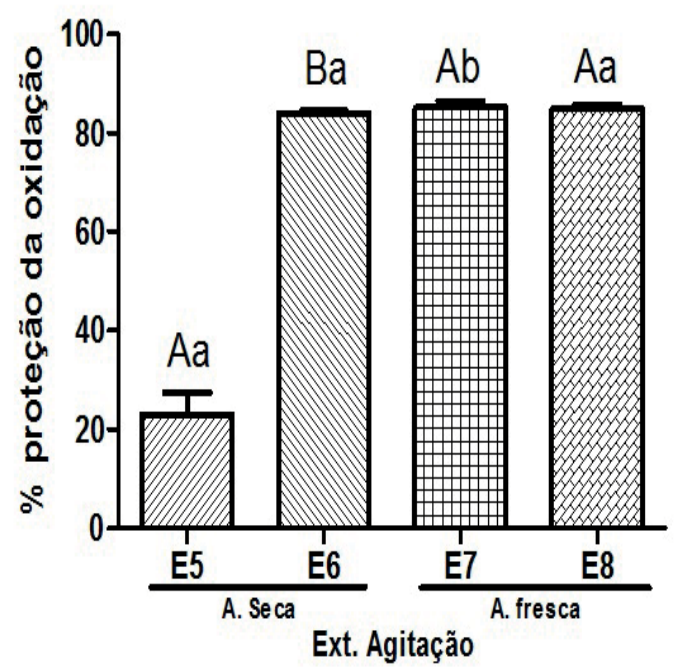

D

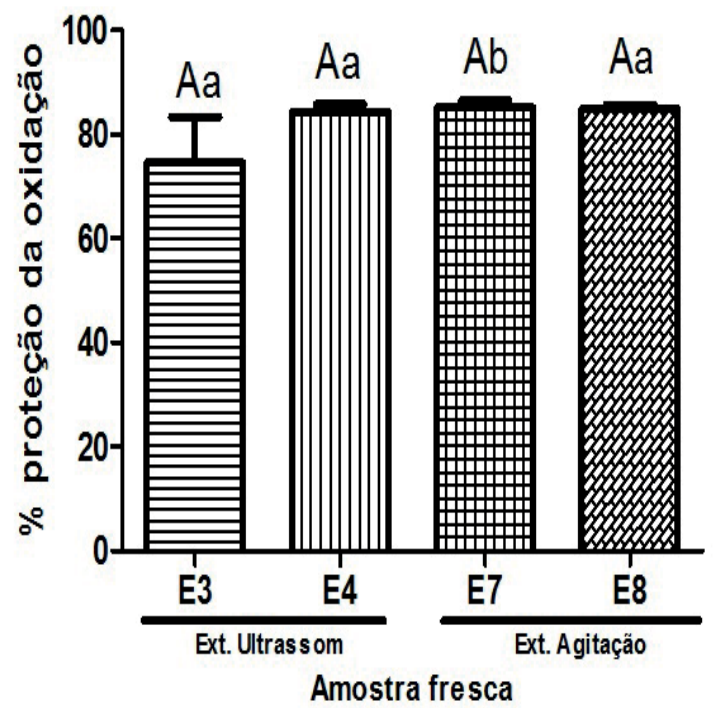

FIGURA 2. PROTEÇÃO ANTIOXIDANTE EXPRESSA EM PORCENTAGEM DE INIBIÇÃO DA OXIDAÇÃO PELO MÉTODO DO DPPH EXTRATO ACETÔNICO (E1 E E5); EXTRATO HIDROMETANÓLICO (E2 E E6); EXTRATO ACETÔNICO (E3 E E7); EXTRATO HIDROMETANÓLICO (E4 E E8)

Nas figuras $2 \mathrm{~A}$ e $2 \mathrm{~B}$, as letras maiúsculas comparam diferentes solventes em um mesmo tipo de amostra, e as letras minúsculas comparam um mesmo tipo de solvente em diferentes amostras. Nas figuras $2 \mathrm{C}$ e 2D, as letras maiúsculas comparam diferentes métodos de extração em um mesmo tipo de solvente, e as letras minúsculas comparam um mesmo tipo de solvente em diferentes métodos de extração. Letras diferentes indicam diferenças estatisticamente significativas $(p<0.05)$.

O teste tem a vantagem de ser fácil e rápido, além disso, apresenta boa estabilidade, sensibilidade e não necessita de preparação especial (DENG et al., 2011; MUSA et al., 2013). Além disso, a expressão da atividade em TEAC (Trolox® Equivalent Antioxidant Capacity) permite avaliar a ação antioxidante dos compostos bioativos extraídos comparado a um composto de reconhecida atividade antioxidante (Trolox®). Isso permite validar a eficiência dos compostos testados. 
A

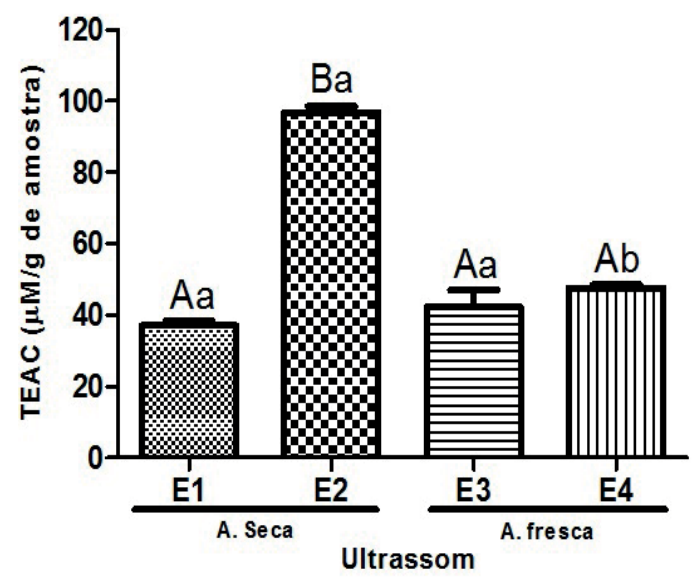

C

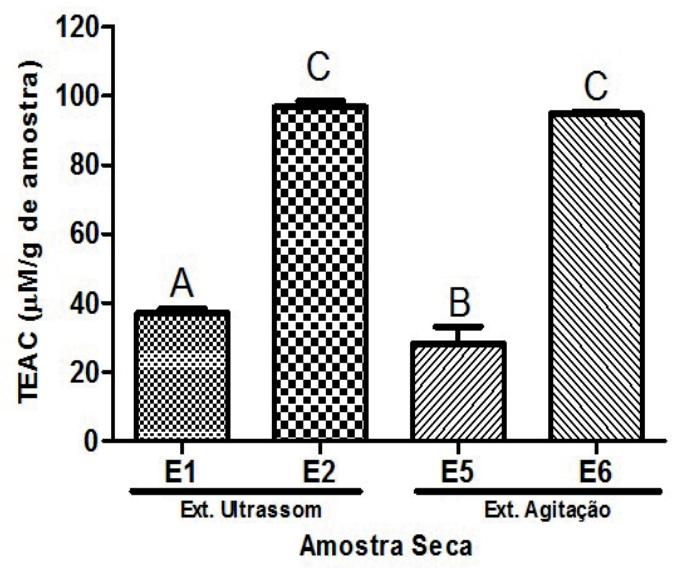

B

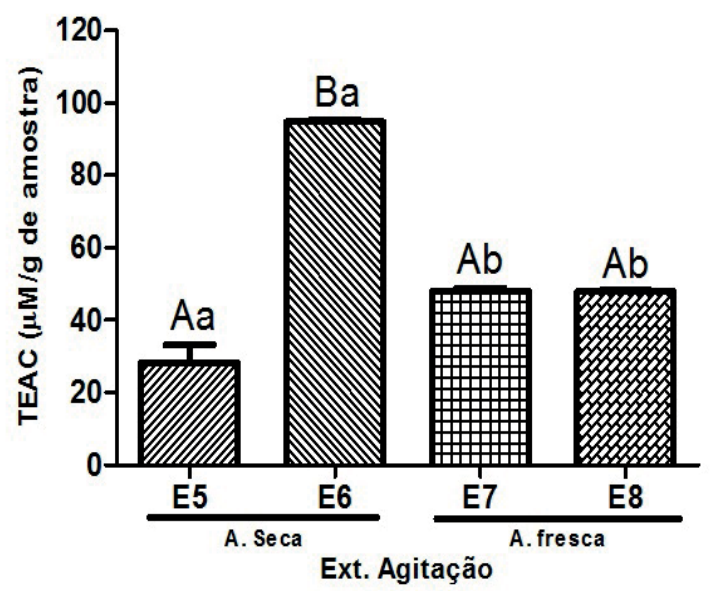

D

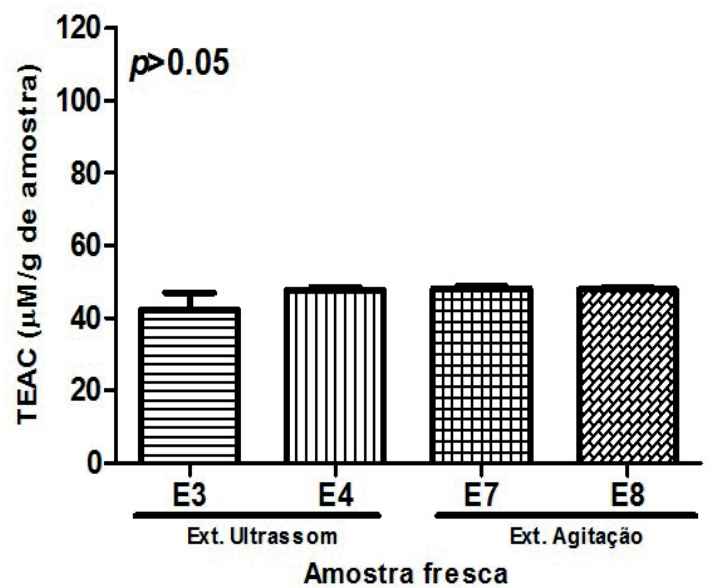

FIGURA 3. COMPARAÇÃO DOS VALORES DE TEAC (TROLOX® EQUIVALENT ANTIOXIDANT CAPACITY) PELO MÉTODO DO DPPH. EXTRATO ACETÔNICO (E1 E E5); EXTRATO HIDROMETANÓLICO (E2 E E6); EXTRATO ACETÔNICO (E3 E E7); EXTRATO HIDROMETANÓLICO (E4 E E8)

Nas figuras $3 \mathrm{~A}$ e $3 \mathrm{~B}$, as letras maiúsculas comparam diferentes solventes em um mesmo tipo de amostra, e as letras minúsculas comparam um mesmo tipo de solvente em diferentes amostras. Nas figuras $3 \mathrm{C}$ e $3 \mathrm{D}$, as letras maiúsculas comparam diferentes métodos de extração em um mesmo tipo de solvente. Letras diferentes indicam diferenças estatisticamente significativas $(p<0.05)$.

\subsection{AVALIAÇÃO DA ATIVIDADE ANTIOXIDANTE: MÉTODO ABTS•+}

Nas figuras 4A a 4D são mostradas as ações antioxidante dos extratos obtidas segundo o método de sequestro do radical ABTS ${ }^{\bullet}$. Corroborando a maior ação dos extratos hidrometanólicos secos obtidos tanto por ultrassom como por agitação contínua, foram encontrados valores de 781,7 $\mu \mathrm{M}$ e 726,7 $\mu \mathrm{M}$ equivalentes de Trolox®/g de amostra, respectivamente. Não houve diferença estatística entre as metodologias de extração, porém houve em relação aos demais solventes e tipos de amostras.

Alguns autores têm avaliado diferentes extratos preparados com espécies de E. tirucalli e têm reportado valores bastante variáveis quanto a atividade antioxidante. Essas variações de resultados são em razão do tipo de método que é utilizado para testar a capacidade antioxidante, como também pela forma de expressar os resultados. Porém, todos relatam uma importante atividade antioxidante nessa espécie, especialmente quando se utiliza solventes orgânicos ou misturas aquosas com 
solventes orgânicos. Por exemplo, MUNRO et al. (2015) avaliaram extratos aquosos e metanólicos de E. tirucalli quanto a atividade antioxidante e os resultados demonstraram resposta dose-dependente quanto a concentração dos compostos sólidos nos extratos. Entretanto, o desempenho dos extratos metanólicos foram superiores aos extratos aquosos, especialmente quando aplicado o teste DPPH. Os autores do estudo argumentam que é difícil comparar quantitativamente os resultados de atividade antioxidante em extratos devido a natureza variável dos processos químicos envolvidos nas diferentes metodologias, e portanto, a tendência comportamental dos valores é um parâmetro mais objetivo. Além disso, os solventes orgânicos, tal como o metanol, possuem maior coeficiente de partição, o que permite uma maior extração dos compostos fenólicos (MUNRO et al., 2015). Outro estudo realizado por NDAM et al. (2016) com extratos acetônicos da espécie E. golondrina mostrou também uma atividade antioxidante dose-dependente em relação a concentração de sólidos extraídos. Na concentração de $0,5 \mathrm{mg} / \mathrm{mL}$, os referidos autores obtiveram valores próximos a $80 \%$ em relação a ação antioxidante da vitamina $\mathrm{C}$, quando avaliados pela metodologia do ABTS. Os resultados nesse presente estudo foram expressos em TEAC, mas mostraram uma maior eficiência de extração de compostos bioativos que conferem atividade antioxidante nos extratos hidrometanólicos.

A

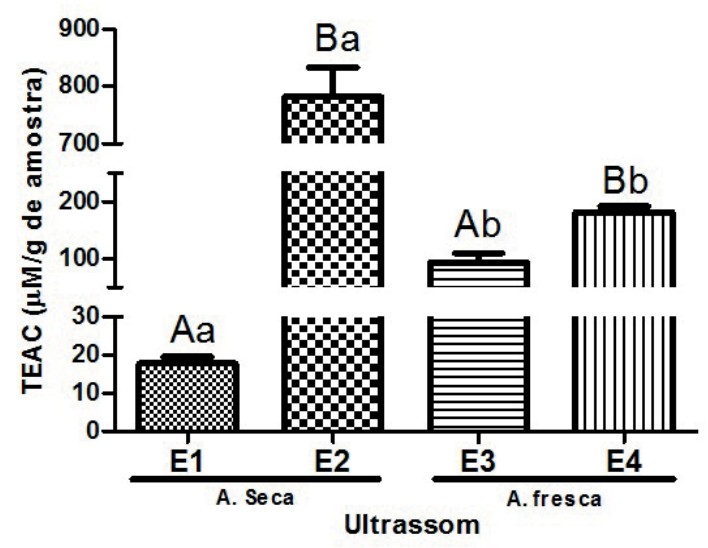

C

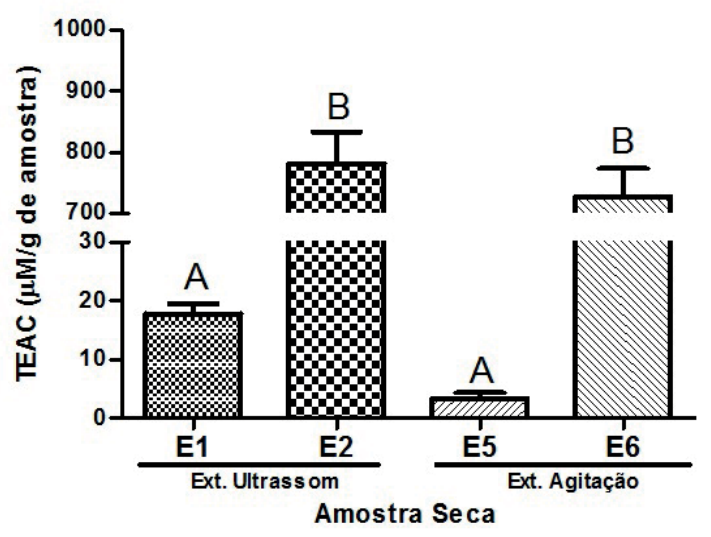

B

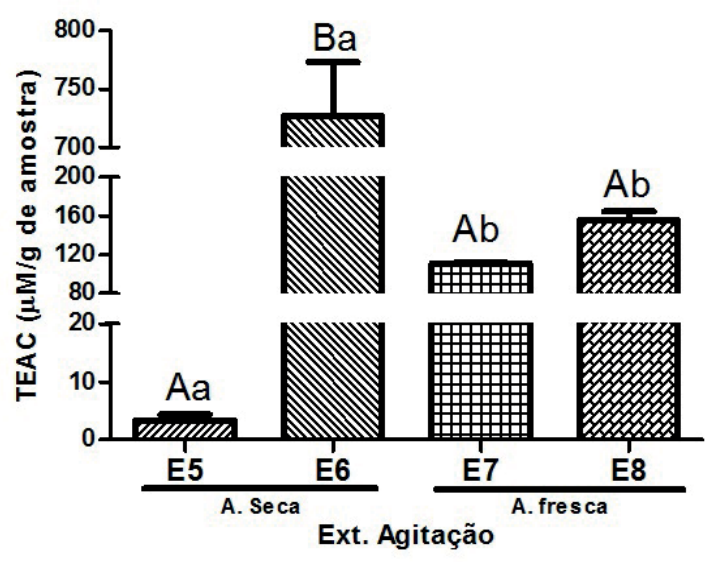

D

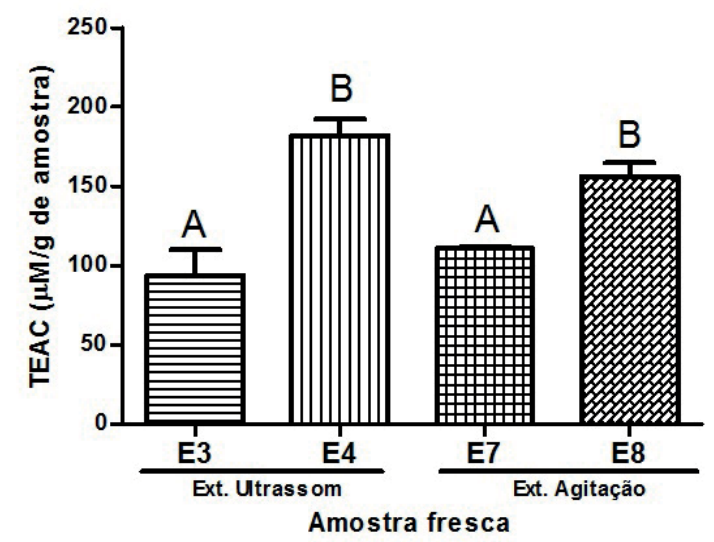

FIGURA 4. COMPARAÇÃO DOS VALORES DE TEAC (TROLOX® EQUIVALENT ANTIOXIDANT CAPACITY) PELO MÉTODO DO ABTS. EXTRATO ACETÔNICO (E1 E E5); EXTRATO HIDROMETANÓLICO (E2 E E6); EXTRATO ACETÔNICO (E3 E E7); EXTRATO HIDROMETANÓLICO (E4 E E8)

Nas figuras 4A e 4B, as letras maiúsculas comparam diferentes solventes em um mesmo tipo de amostra, e as letras minúsculas comparam um mesmo tipo de solvente em diferentes amostras. Nas figuras 4C e 4D, as letras maiúsculas comparam diferentes métodos de extração em um mesmo tipo de solvente. Letras diferentes indicam diferenças estatisticamente significativas $(p<0.05)$. 
Outra fator que influencia a eficiência na extração dos compostos bioativos de plantas é a realização do processo de extração em amostras secas ou frescas. O presente estudo mostrou que extratos produzidos a partir das amostras secas apresentam ações antioxidantes maiores quando comparados com extratos produzidos a partir de amostras frescas. Resultados similares e corroborantes do presente estudo também são reportados por DE ARAÚJO et al. (2014) que analisaram diferentes extratos da espécie E. tirucalli produzidos com diferentes amostras (seca ou fresca) e diferentes solventes (acetona e hidrometanol). Os resultados desse referido trabalho mostraram que extratos hidrometanólicos produzido com amostras secas possuem maior atividade antioxidante.

Em relação a metodologia utilizada, convém ressaltar algumas de suas características analíticas. O método do radical $\mathrm{ABTS}^{\cdot+}$ baseia-se no monitoramento, por espectrofotômetro da redução do cátion $A B T S^{\bullet+}$ na presença de algum antioxidante (MOON e SHIBAMOTO 2009). Os resultados da atividade antioxidante são expressos como valor TEAC (capacidade antioxidante total equivalente ao TROLOX®), onde TROLOX® é um análogo sintético à vitamina $\mathrm{E}$ utilizado como antioxidante de referência (RE et al., 1999). Isso fornece uma estimativa da quantidade de moléculas de radicais consumidas pelo antioxidante, uma vez que o valor TEAC caracteriza a capacidade da amostra testada em reagir com o radical ABTS •+ (MAGALHÃES et al., 2008).

$O$ teste de $A B T S^{\bullet+}$ é considerado simples e muito utilizado em laboratórios. Entre suas vantagens destaca-se o baixo custo do material, tempo reduzido de execução (MONIRUZZAMAN et al., 2012), a possibilidade do estudo em uma grande faixa de pH (KARADAG et al., 2009) sem variar o potencial redox (BACH et al., 2013).

Numa análise generalista, os extratos que apresentaram maiores valores de atividades antioxidantes avaliadas pelas duas metodologias (DPPH e ABTS ${ }^{\bullet+}$ ) também apresentaram maiores teores de compostos fenólicos. Nesse contexto, destacam-se mais uma vez os extratos hidrometanólicos secos obtidos tanto por ultrassom como por agitação contínua. Tais resultados corroboram com aqueles encontrados por De Araújo et al. (2014), na qual observou a correlação positiva entre extratos com maiores teores de compostos fenólicos totais e maiores atividades antioxidantes.

\subsection{ENSAIO DE VIABILIDADE CELULAR}

As figuras $5 \mathrm{~A}$ e $5 \mathrm{~B}$ mostram o padrão morfológico do tapete celular formado pelas células LCC-MK ${ }_{2}$ presentes no cultivo do controle negativo (em meio de cultura apenas) e positivo (contendo DMSO) utilizados no teste de avaliação morfológica. Neste experimento, é possível observar claramente a intensa destruição do tapete celular no controle positivo.
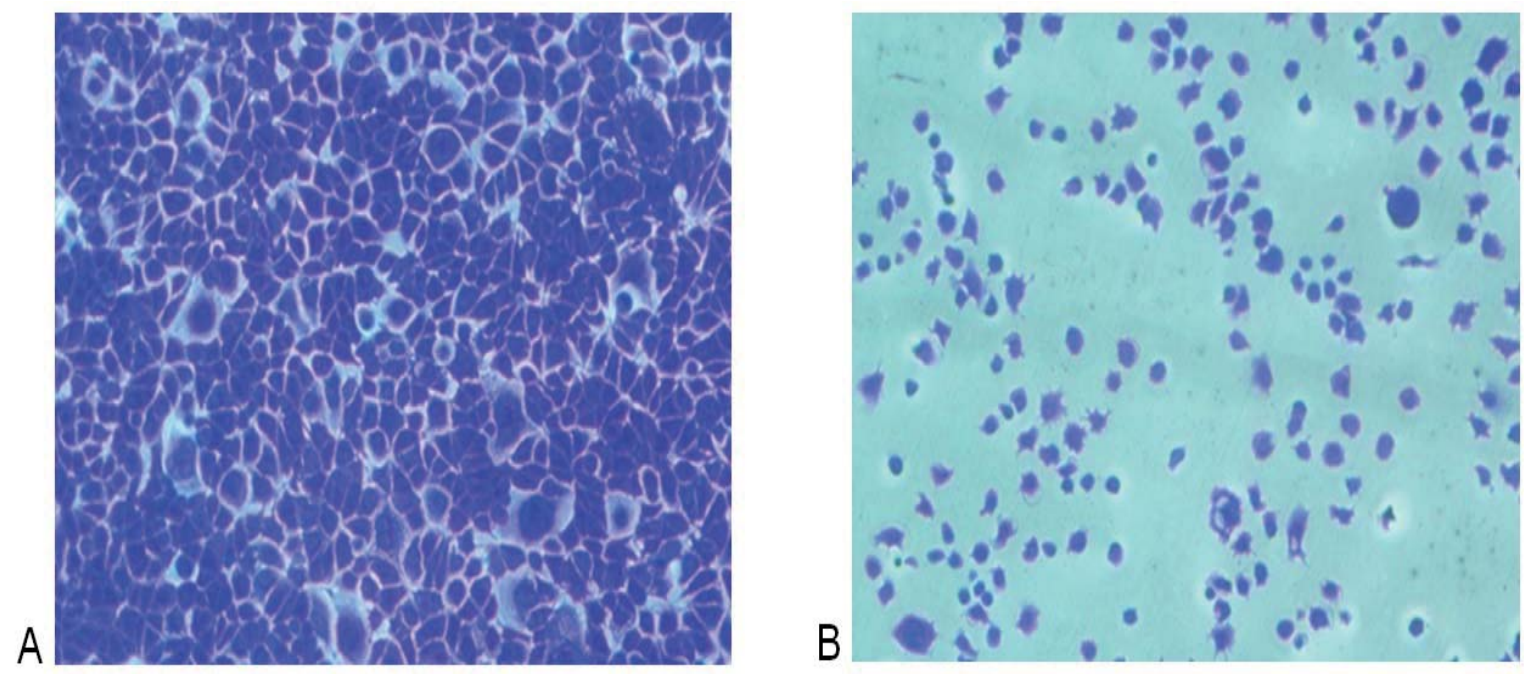

FIGURA 5. MORFOLOGIA DO TAPETE CELULAR OBTIDO EM CULTURA SOMENTE COM O MEIO (A) CONTROLE NEGATIVO E NA PRESENÇA DO DMSO COMO (B) CONTROLE POSITIVO. 
Na figura 6 está esquematizado o resultado das avaliações morfológicas das células frente às diferentes concentrações utilizadas. Pode-se observar que até a concentração de $2 \mathrm{mg} / \mathrm{mL}$ as células não apresentaram perturbações da viabilidade celular para o DMSO, apresentando efeito citotóxico nas concentrações acima deste valor e podendo ser utilizado como controle positivo interferente na viabilidade celular.

O composto fenólico ácido ferúlico isolado foi a única amostra teste que não alterou a viabilidade das células $L C C-M K_{2}$. Em relação aos extratos obtidos de $E$. tirucalli $L$., observou-se que as amostras E8, E2 e E4 foram aquelas que menos alteraram a viabilidade celular, pois não foram observadas alterações morfológicas em concentrações de até $2 \mathrm{mg} / \mathrm{mL}, 1 \mathrm{mg} / \mathrm{mL}, 1 \mathrm{mg} / \mathrm{mL}$, respectivamente. Entretanto, para os demais extratos E1, E6, E3 e E5 alguma alteração morfológica foi observada em concentrações acima de $0,5 \mathrm{mg} / \mathrm{mL}, 0,5 \mathrm{mg} / \mathrm{mL}, 0,2 \mathrm{mg} / \mathrm{mL}, 0,2 \mathrm{mg} / \mathrm{mL}$, respectivamente.

A análise de viabilidade celular pela capacidade de metabolizar o reagente MTT foi similar à observada na análise morfológica.

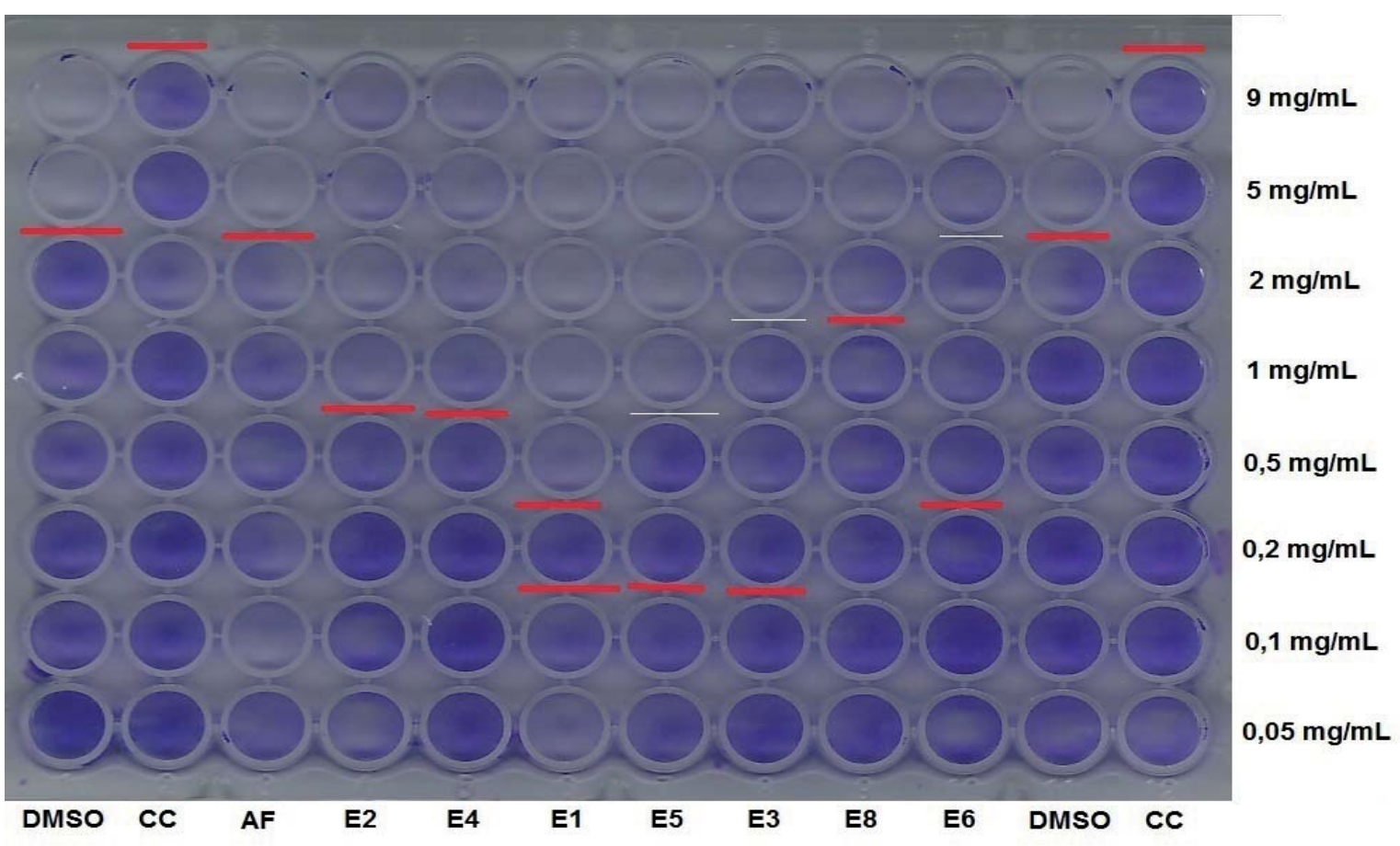

\section{FIGURA 6. ESQUEMATIZAÇÃO DA PLACA DE MICROTITULAÇÃO UTILIZADA PARA A DETERMINAÇÃO DA VIABILIDADE CELULAR POR ANÁLISE MORFOLÓGICA E ENSAIO DO MTT, DOS EXTRATOS DE EUPHORBIA TIRUCALLI L. E O COMPOSTO FENÓLICO ISOLADO ÁCIDO FERÚLICO SOBRE CÉLULAS LCC-MK $K_{2}$}

As concentrações variaram de 0,05 a $9 \mathrm{mg} / \mathrm{mL}$. CC: controle negativo de células somente com meio de cultura; AF: ácido ferúlico; extratos E1: acetônico seco/ultrassom; E2: hidrometanólico seco/ultrassom; E3: acetônico fresco/ultrassom; E4: hidrometanólico fresco/ultrassom; E5: acetônico seco/agitação contínua; E6: hidrometanólico seco/agitação contínua; E8: hidrometanólico fresco/agitação contínua.

A identificação de compostos químicos naturais com atividade terapêutica pode levar ao desenvolvimento de novos biofármacos que provoquem menos efeitos adversos do que os fármacos convencionais (BONIFÁCIO et al., 2014). Entretanto, apesar de ser oriundo de uma fonte natural, isso não implica afirmar que tais compostos não apresentem riscos tóxicos à saúde humana ou animal (JUNIOR, 2008). Todo composto químico, independentemente da fonte de origem, é passível de concentrações tóxicas, anulando o conceito popular equivocadamente criado que por serem de origem natural são absolutamente seguros com nenhum ou pouco efeito secundário (OWENS et al., 2014). Assim, investigações em relação à eficácia e seus efeitos toxicológicos adversos são essenciais (DALAR et al., 2012; ATTANAYAKE et al., 2013). 


\subsection{AVALIAÇÃO DA ATIVIDADE ANTIPARASITÁRIA}

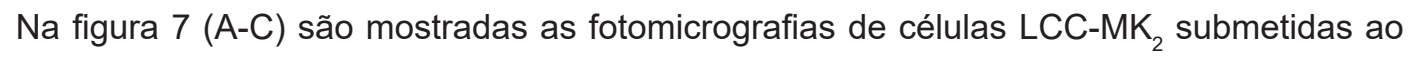
teste de infectividade pela forma tripomastigota de Trypanosoma cruzi. Não foram observadas diferenças na porcentagem de células infectadas e tratadas com os diferentes extratos ou com o ácido ferúlico em relação aos controles não tratados. O percentual de células infectadas foi entre $72-80 \%$ para todas as preparações-teste.
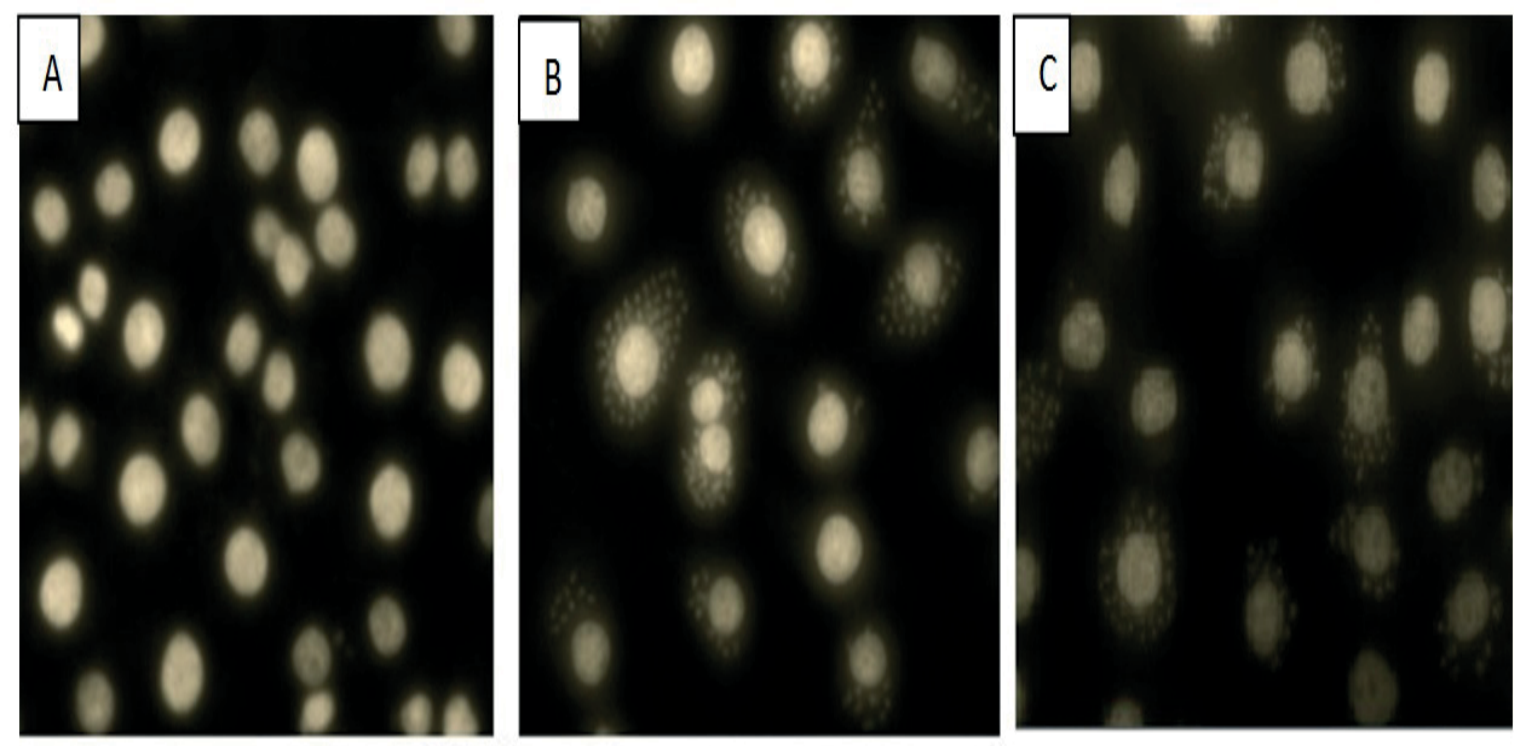

FIGURA 7. FOTOMICROGRAFIAS DE CÉLULAS LCC-MK $K_{2}$ SUBMETIDAS AO TESTE DE INFECTIVIDADE PELA FORMA TRIPOMASTIGOTA DE TRYPANOSOMA CRUZI

(A) células controle-negativas; (B) células controle-positivas infectadas com T. cruzi; (C) células teste infectadas com T. cruzi e tratadas com o ácido ferúlico isolado (representativo dos demais extratos, por não terem apresentado diferenças no percentual de infectividade celular).

Jimenez et al. (2014), ao avaliar a atividade tripanocida de duas lactonas sesquiterpênicas helenalin (HLN) e dehydroleucodine (DHL) isoladas das partes aéreas de Gaillardia megapotamica e Artemisia douglasiana Besser, respectivamente, constatou diminuição da viabilidade de tripomastigotas de $T$. cruzi tratados com HLN e DHL em $65,4 \pm 3,2 \%$ e $40,1 \pm 1,2 \%$, respectivamente. Em outro estudo, Hamedt et al. (2014) avaliou a atividade tripanocida de extratos e frações da planta Piper jericoense, e na análise de uma das frações obteve um $I_{50}$ de $98 \mu \mathrm{g} / \mathrm{mL}$ para forma tripomastigota de T. cruzi. Estudos desta natureza demonstram a importância de se investigar extratos de plantas e seus compostos isolados como fonte de novas drogas com atividade tripanocida, principalmente, considerando o fato de ser uma importante doença de caráter negligenciado.

\section{CONCLUSÃO}

Com base nos resultados mostrados neste trabalho, foi possível concluir que a metodologia de extração por ondas ultrassônicas é mais eficiente para extração dos compostos fenólicos. Os extratos hidrometanólicos das amostras secas apresentaram maior quantidade de compostos fenólicos e maior atividade antioxidante. De forma preliminar, não foram demonstradas atividades antiparasitárias dos extratos e do ácido ferúlico isolado, quando testados sobre as formas tripomastigotas de Trypanosoma cruzi. O composto fenólico ácido ferúlico, quando testado isoladamente, não apresentou efeito citotóxico até a concentração de $2 \mathrm{mg} / \mathrm{mL}$. 


\title{
ABSTRACT \\ EUPHORBIA TIRUCALLI L.: AN EVALUATION OF BIOLOGICAL ACTIVITIES OF EXTRACTS OBTAINED BY CONVENTIONAL AGITATION AND ULTRASOUND-ASSISTED METHODS
}

\begin{abstract}
Plant extracts have bioactive compounds showing many possibilities for their applications in biotechnological, pharmaceutical and food industries. This study evaluated different extracts from Euphorbia tirucalli L. species cultivated on Piauí state's coast. Total phenolic compounds and antioxidant activities were quantified in the different extracts. Additionally, cell viability and antiparasitic activity were also investigated. Acetonic or hydromethanolic extracts were obtained by continuous stirring or ultrasound-assisted extraction. Antioxidant activities were analyzed by DPPH ${ }^{\bullet}$ and $\mathrm{ABTS}^{{ }^{+}}$methodologies. Antiparasitic activity was investigated by cell infectivity assay with trypomastigotes of Trypanosoma cruzi. Cell viability was morphological and metabolically assessed on LLC-MK ${ }_{2}$ cells and MTT assay. Total phenolic compounds ranged from 0.65 to $13.78 \mathrm{mgGAE} / \mathrm{g}$. These values were statistically different $(p<0.05)$ for extracts prepared with both different solvents and extraction methods. Hydromethanolic extracts showed highest values compared to acetonic extracts. Extractions from dried samples were more efficient under both conventional continuous stirring (12.48 $\pm 0.34 \mathrm{mgGAE} / \mathrm{g})$ and ultrasound-assisted extraction $(13.78 \pm 0.14 \mathrm{mgGAE} / \mathrm{g})$. Extracts showing highest antioxidant activities measured by $\mathrm{DPPH}^{\bullet}$ and $\mathrm{ABTS} \mathrm{S}^{\cdot+}$ essays also showed highest levels of phenolic compounds. Cytotoxic concentrations ranged from $0.2 \mathrm{mg} / \mathrm{mL}$ to $2 \mathrm{mg} / \mathrm{mL}$ depending on the evaluated extract. However, isolated ferulic acid showed no cytotoxicity up to concentration of $2 \mathrm{mg} / \mathrm{mL}$. Preliminarly, both extracts and isolated ferulic acid did not showed antiparasitic activity. Overall, hydromethanolic extracts of Euphorbia tirucalli L. obtained from dry samples and submitted to ultrasound-assisted extraction showed the highest phenolic compound contents and considerable antioxidant activities.
\end{abstract}

KEYWORDS: ANTIOXIDANT ACTIVITY; ANTIPARASITIC ACTIVITY; EUPHORBIA TIRUCALLI L., FERULIC ACID.

\section{REFERÊNCIAS}

1 ABREU, C.M.; PRICE, S.L.; SHIRK, E.N.; CUNHA, R.D, PIANOWSKI, L.F.; CLEMENTS, J.E.; TANURI, A.; GAMA, L. Dual role of novel ingenol derivatives from Euphorbia tirucalli in HIV replication: inhibition of de novo infection and activation of viral LTR. PLos One, v.9, n.5, p.1-14, 2014.

2 ALAN, A.; JURAIMI, A.B.; HAMID, A.B.; ASLANI, F.; HASAN, M.M.; ZAINUDIN, M.A.M. UDDIN, K. Evaluation of Antioxidant Compounds, Antioxidant Activities, and Mineral Composition of 13 Collected Purslane (Portulaca oleracea L.) Accessions. BioMed Research International, v.2014, n.1, p.1-10, 2014.

3 ALTEMINI, A.; WATSON, D.G.; CHOUDHARY, R.; DASARI, M.R.; LIGHTFOOT, D.A. Ultrasound assisted extraction of phenolic compounds from peaches and pumpkins. PLoS ONE, v.11, n. 2, e0148758, 2016.

4 ASWAR, U.; MAHAJAN, U.; NERURKAR, G.; ASWAR, M. Amelioration of cardiac hypertrophy induced by abdominal aortic banding in ferulic acid treated rats. Biomedicine \& Aging Pathology, v.3, n.4, p.209-217, 2013.

5 ATTANAYAKE, A.P.; JAYATILAKA, K.A.P.W.; PATHIRANA, C.; MUDDUWA, L.K.B. Efficacy and $\mathrm{t}$ o $\mathrm{x}$ i $\mathrm{c}$ o I $\mathrm{o} \mathrm{g}$ i $\mathrm{c}$ a $\mathrm{l}$ evaluation of Coccinia grandis (Cucurbitaceae) extract in male Wistar rats. Asian Pacific Journal of Tropical Disease, v.3, n.6, p.460-466, 2013.

6 BACH, C.E.; WARNOCK, D.D.; HORN, D.J.V.; WEINTRAUB, M.N.; SINSABAUGH, R.L.; ALLISON, $\quad$ S . D . ; GERMAN, D.P. Measuring phenol oxidase and peroxidase activities with pyrogallol, L-DOPA, and ABTS: Effect of assay conditions and soil type. Soil Biology and Biochemistry, v.67, n.1, p.183-191, 2013.

7 BALASUNDRAM, N., SUNDRAM, K., SAMMAN, S. Phenolic compounds in plants and agri-industrial by-products: 
Antioxidant activity, occurrence and potencial uses. Food Chemistry, v.99, n.1, p.191-203, 2006.

8 BANI, S.; KAUL, A.; KHAN, B.; GUPTA, V.K.; SATTI, N.K.; SURI, K.A.; QAZI, G.N. Anti-arthritic activity of a biopolymeric fraction from Euphorbia tirucalli. Journal of Ethnopharmacology, v.110, n.1 p.92-98, 2007.

9 BARRERA-VÁZQUEZ, M.F.; COMINI, L.R.; MARTINI, R.E.; NÚÑEZ-MONTOYA, S.C.; BOTTINI, S.; CABRERA, J.L. Comparisons between conventional, ultrasound-assisted and microwave-assisted methods for extraction of anthraquinones from Heterophyllaea pustulata Hook f. (Rubiaceae). Ultrasonics Sonochemistry, v. 21, n.2, pp. 478484, 2014.

10 BASKARAN, N.; MANOHARAN, S.; BALAKRISHNAN, S.; PUGALENDHI, P. Chemopreventive potential of ferulic acid in 7,12-dimethylbenz[a]anthracene-induced mammary carcinogenesis in Sprague-Dawley rats. European Journal of Pharmacology, v.637, n.3, p. 22-29, 2010.

11 BASMA, A.A.; ZAKARIA, Z.; LATHA, L.Y.; SASIDHARAN, S. Antioxidant activity and phytochemical screening of the methanol extracts of Euphorbia hirta L. Asian Pacific Journal of Tropical Medicine, v.1, n.1, p. 386-390, 2011.

12 BEN MOHAMED MAOULAININE, L.; JELASSI, A.; HASSEN, I.; OULD MOHAMED SALEM OULD BOUKHARI, A. Antioxidant proprieties of methanolic and ethanolic extracts of Euphorbia helioscopia, (L.) aerial parts. International Food Research Journal, v. 19, n. 3, p. 1125-1130, 2012.

13 BLOIS, M.S. Antioxidant determinations by the use of a stable free radical. Nature, v.181, n.1, p.1199-1200, 1958.

14 BONIFÁCIO, B.V.; DA SILVA, P.B.; RAMOS, M.A.S.; NEGRI, K.M.S.; BAUAB, T.M.; CHORILLI, M. Nanotechnologybased drug delivery systems and herbal medicines: a review. International Journal of Nanomedicine, v.9, n.1, p.1-15, 2013.

15 BRAND-WILLIAMS, W.; CUVELIER, M.E.; BERSET, C. Use of a free radical method to evaluate antioxidant activity. LWT - Food Science and Technology, v.28, n.1, p.25-30, 1995.

16 CHARPE, T.W.; RATHOD, V.K. kinetics of ultrasound assisted extraction of wedelolactone from Eclipta alba. Brazilian Journal of Chemical Engineering, v. 33, n.4, p. 1003-1010, 2016.

17 CHEMAT, F.; ROMBAUT, N.; SICAIRE, A-G.; MEULLEMIESTRE, A.; FABIANO-TIXIER, A-S.; ABERT-VIAN, M. Ultrasound assisted extraction of food and natural products. Mechanisms, techniques, combinations, protocols and applications: A Review. Ultrasonics Sonochemistry, v. 34, p. 540-560, 2016.

18 CHENG, Z.; MOORE, J.; YU, L.L. High-Throughput Relative DPPH Radical Scavenging Capacity Assay. Journal of Agricultural and Food Chemistry, v.54, n.20, p.7429-7436, 2006.

19 DALAR, A.; TÜRKER, M.; KONCZAK, I. Antioxidant capacity and phenolic constituents of Malva neglecta Wallr. and Plantago lanceolata L. from Eastern Anatolia Region of Turkey. Journal of Herbal Medicine, v.2, n.1, p.42-51, 2012.

20 DAWIDOWICZ, A.L.; WIANOWSKA, D.; OLSZOWY, M. On practical problems in estimation of antioxidant activity of compounds by DPPH method (Problems in estimation of antioxidant activity). Food Chemistry, v.131, n.3, p.1037-1043, 2012.

21 DE ARAÚJO, K.M.; LIMA, A.; SILVA, A.L.; RODRIGUES, L.L.; AMORIM, A.G.N.; QUELEMES, P.V.; SANTOS, R.C.; ROCHA, J.A.; ANDRADES, E.O.; LEITE, J.R.S.A.; MANCINI-FILHO, J.; TRINDADE, R.A. Identification of Phenolic Compounds and Evaluation of Antioxidant and Antimicrobial Properties of Euphorbia Tirucalli L. Antioxidants, v.3, n.1, p.159-175, 2014.

22 DENG, J.; CHENG, W.; YANG, Y. A novel antioxidant activity index (AAU) for natural products using the DPPH assay. Food Chemistry, v.125, n.4, p.1430-1435, 2011.

23 DZOYEM, J.P.; ELOFF, J.N. Anti-inflammatory, anticholinesterase and antioxidant activity of leaf extracts of twelve plants used traditionally to alleviate pain and inflammation in South Africa. Journal of Ethnopharmacology, v.160, n.3, p.194201,2015

24 DUTRA, R.C.; CLAUDINO, R.F.; BENTO, A.F.; MARCON, R.; SCHMIDT, E.C.; BOUZON, Z.L.; PIANOWSKI, L.F.; CALIXTO, J.B. Preventive and therapeutic euphol treatment attenuates experimental colitis in mice. PLos One, v.6 , n.11, p.1-15, 2011.

25 EBRAHIMI, A.; SCHLUESENER H. Natural polyphenols against neurodegenerative disorders: potentials and pitfalls. Ageing Research Reviews, v.11, n.2, p.329-345, 2012.

26 EKLUND, P.C.; LANGVIK, O.K.; WARNA, J.P.; SALMI, T.O.; WILLFOR, S.M.; SJOHOLM, R.E. Chemical studies on antioxidant mechanisms and free radical scavenging properties of lignans. Organic \& Biomolecular Chemistry, v.3, n.18, p.3336-3347, 2005. 
27 GHASEMZADEH, A; ZE JAAFAR, H. Profiling of phenolic compounds and their antioxidant and anticancer activities in pandan (Pandanus amaryllifolius Roxb.) extracts from different locations of Malaysia. BMC Complementary and Alternative Medicine, v.13, n. 341, p.1-9, 2013.

HAMEDT, A.L.; ORTIZ, I.C.; GARCÍA-HUERTAS, P.A.; SÁENZ, J.; ARAUJO, A.C.; DE MATTOS, J.C.P.; RODRÍGUEZGAZQUEZ, M.A.; TRIANA-CHÁVEZ, O. Cytotoxic, mutagenic and genotoxic evaluation of crude extracts and fractions from Piper jericoense with trypanocidal action. Acta Tropica, v.131, n.1, p.92-97, 2014.

30 HE, B.; ZHANGA, L-L.; YUE, X-Y.; LIANG, J.; JIANG, J.; GAO, X-L.; YUE, P-X. Optimization of Ultrasound-Assisted Extraction of phenolic compounds and anthocyanins from blueberry (Vaccinium ashei) wine pomace. Food Chemistry, v. 204 , n.1, p. $70-76,2016$

31 HEINEN, T.E.; DE fARIAS, C.B.; ABUJAMRA, A.L.; MENDONÇA, R.Z.; ROESLER, R.; DA VEIGA, A.B. Effects of Lonomia obliqua caterpillar venom upon the proliferation and viability of cell lines. Cytotechnology, v.66, n.1, p.63-64, 2014.

32 HOSSAIN, M.B.; BARRY-RYAN, C.; MARTIN-DIANA, A.B.; BRUNTON, N.P. Effect of drying method on the antioxidant capacity of six Lamiaceae herbs. Food Chemistry, v. 123, p. 85-91, 2010.

33 JIMENEZ, V.; KEMMERLING, U.; PAREDES, R.; MAYA, J. D.; SOSA, M. A.; GALANTI, N. Natural sesquiterpene lactones induce programmed cell death in Trypanosoma cruzi: A new therapeutic target?. Phytomedicine, v.21, n.11, p.1411-1418, 2014

34 JUNIOR, V.F.V. Estudo do consumo de plantas medicinais na Região Centro-Norte do Estado do Rio de Janeiro: aceitação pelos profissionais de saúde e modo de uso pela população. Revista Brasileira de Farmacognosia, v.18, n. 2, p.308-313, 2008.

35 KARADAG, A.; OZCELIK, B.; SANER, S. Review of Methods to Determine Antioxidant Capacities. Food Analytical Methods, v.2, n.1, p.41-60, 2009.

36 LAHLOU, F.A.; HMIMID, F.; LOUTFI, M.; BOURHIM, N. Antioxidant activity and quantification of phenolic compounds of Euphorbia echinus. International Journal of Pharmacy and Pharmaceutical Sciences, v. 6, s. 2, p. 357-360, 2014.

37 LI, H.; WANG, X.; LI, Y.; LI, P.; WANG, H. Polyphenolic compounds and antioxidant properties of selected China wines. Food Chemistry, v.112, n.2, p.454-460, 2009.

38 LIMA, A. Caracterização Química, Avaliação da Atividade Antioxidante in vitro e in vivo, e Identificação dos Compostos Fenólicos Presentes no Pequi (Caryocar brasiliense, Camb.). 2008. 182p. Tese (Doutorado em Ciências dos Alimentos) - Faculdade de Ciências Farmacêuticas, Universidade Estadual de São Paulo, São Paulo, 2008.

39 MA, Y.; YE, X.; FANG, Z.; CHEN, J.; XU, G.; LIU, D. Phenolic compounds and antioxidant activity of extracts from ultrasonic treatment of Sastsuma mandarim (Citrus unshiu Marc.) peels. Journal of Agricultural and Food Chemistry, v.56, n.14, p.5682-5690, 2008.

40 MAGALHÃES, L.M.; SEGUNDO, M.A.; REIS, S.; LIMA, J.L.F.C. Methodological aspects about in vitro evaluation of antioxidant properties. Analytica Chimica Acta, v.613, n.1, p.1-19, 2008.

41 MALES, Z.; PILEPIC, K.H.; PETROVIC, L.; BAGARIC, I. Quantitative analysis of phenolic compounds of Inula candida (L.) Cass. Periodicum Biologorum, v.112, n.3, p.307-310, 2010.

42 MELO, J.G.; SANTOS, A.G.; AMORIM, E.L.C.; NASCIMENTO, S.C.; ALBUQUERQUE, U.P. Medicinal plants used as antitumor agents in Brazil: An ethnobotanical approach. Evidence-Based Complementary and Alternative Medicine, v.2011, n.1, p.1-14, 2011.

43 MILARDOVIC, S.; IVEKOVIC, D.; GRABARIC, B.S. A novel amperometric method for antioxidant activity determination using DPPH free radical. Bioelectrochemistry, v.68, n.2, p.175-180, 2006.

44 MOON, J.K.; SHIBAMOTO, T. Antioxidant Assays for Plant and Food Components. Journal of Agricultural and Food Chemistry, v.57, n.5, p.1655-1666, 2009.

45 MODNICKI, D; LABEDZKA, J. Estimation of the total phenolic compounds in juniper sprouts (Juniperus communis L., Cupressaceae) from different places at the kujawsko-pomorskie province. Herba Polonica Journal, v.55, n.3. p.127132, 2009.

46 MOLYNEUX, P. The use of the stable free radical diphenylpicrylhydrazyl (DPPH) for estimating antioxidant activity. Songklanakarin Journal of Science and Technology, v.26, n.2, p. 211-219, 2004. 
47 MONIRUZZAMAN, M.; KHALIL, M.I.; SULAIMAN, S.A.; GAN, S.H. Advances in the analytical methods for determining the antioxidant properties of honey: a review. African Journal of Traditional, Complementary, and Alternative, v.9, n.1, p.36-42, 2012.

48 MORELLI, L.L.L.; PRADO, M.A. Extraction optimization for antioxidant phenolic compounds in red grape jam using ultrasound with a response surface methodology. Ultrasonics Sonochemistry, v.19, n.6, p.1144-1149, 2012.

49 MUNIN, A.; EDWARDS-LÉVY, F. Encapsulation of Natural Polyphenolic Compounds; a Review. Pharmaceutics, v. 3, n.4, p.793-829, 2011.

50 MUÑIZ-MÁRQUEZ, D.B.; MARTÍNEZ-ÁVILA, G.C.; WONG-PAZ, J.E.; BELMARES-CERDA, R.; RODRÍGUEZHERRERA, R.; AGUILAR, C.N. Ultrasound-assisted extraction of phenolic compounds from Laurus nobilis L. and their antioxidant activity. Ultrasonics Sonochemistry, v. 20, n.5, pp. 1149-1154, 2013.

51 MUNRO, B.; VUONG, Q.V.; CHALMERS, A.C.; GOLDSMITH, C.D.; BOWYER, M.C.; SCARLETT, C.J. Phytochemical, Antioxidant and Anti-Cancer Properties of Euphorbia tirucalli Methanolic and Aqueous Extracts. Antioxidants, v. 4, p. 647-661, 2015.

52 MUSA, K.H.; ABDULLAH, A.; KUSWANDI, B.; HIDAYAT, A.M. A novel high throughput method based on the DPPH dry reagent array for determination of antioxidant activity. Food Chemistry, v.141, n.4 , p.4102-4106, 2013.

53 MURRAY, J. C. BURCH, J.A, STREILEIN, R.D, IANNACCHIONE, M.A, HALL, R.P, PINNELL, S.R. A topical antioxidant solution containing vitamins $C$ and $E$ stabilized by ferulic acid provides protection for human skin against damage caused by ultraviolet irradiation. Journal of the American Academy of Dermatology, v.59, n.3, p.418-425, 2008.

54 NASCIMENTO, A.K.L.; MELO-SILVEIRA, R.F.; DANTAS-SANTOS, N. FERNANDES, J.M.; ZUCOLOTTO, S.M.; ROCHA, H.A.O.; SCORTECCI, K.C. Antioxidant and antiproliferative activities of leaf extracts from Plukenetia volubilis Linneo (Euphorbiaceae). Evidence-Based Complementary and Alternative Medicine, Volume 2013, Article ID 950272, 2013.

55 NDAM, L.M.; MIH, A.M.; TENING, A.S.; FONGOD, A.G.N.; TEMENU, N.A.; FUJII, Y. Phytochemical analysis, antimicrobial and antioxidant activities of Euphorbia golondrina L.C. Wheeler (Euphorbiaceae Juss.): an unexplored medicinal herb reported from Cameroon. Springerplus, v. 5, 264, 2016.

56 OLIVEIRA, D.S.; AQUINO, P.P.; RIBEIRO, S.M.R.; PROENÇA, R.P.C.; PINHEIRO-SANT'ANA, H.M. Vitamina C, carotenoides, fenólicos totais e atividade antioxidante de goiaba, manga e mamão procedentes da ceasa do estado de Minas Gerais. Acta Scientiarum. Health Science, v.33, n.1, p.89-98, 2011.

57 OWENS, C.; BAERGEN, R.; PUCKETT, D. Online Sources of Herbal Product Information. The American Journal of Medicine, v.127, n.2, p.109-115, jan. 2014.

58 PORTO, C.; PORRETTO, E.; DECORTI, D. Comparison of ultrasound-assisted extraction with conventional extraction methods of oil and polyphenols from grape (Vitis vinifera L.) seeds. Ultrasonics Sonochemistry, v. 20, n. 4, pp. 10761080, 2013.

59 RE, R.; PELEGRINI, N.; PROTEGGENTE, A.; PANNACA, A.; YANG, M.; RICE-EVANS, C. Antioxidant activity applying and improved ABTS radical cátion descolorization assay. Free Radical Biology and Medicine, v.26, n.10, p.1231-1237, 1999.

60 SHARMA, O.P.; BHAT, T.K. DPPH antioxidant assay revisited. Food Chemistry, v.113, n.4, p.1202-1205, 2009.

61 SOUZA, M. A. M. Bioacessibilidade dos polifenois naturalmente presentes na folha e no cálice da vinagreira (Hibiscus Sabdariffa L.). 2014. 83p. Dissertação (Mestrado em Alimentos e Nutrição), Universidade Federal do Piauí, Teresina, 2014.

62 SULTANA, R. Ferulic acid ethyl ester as a potential therapy in neurodegenerative disorders. Biochimica et Biophysica Acta (BBA) - Molecular Basis of Disease, v.1822, n.5, p.748-752, 2012

63 SWAIN, T.; HILLS, W.E. The phenolic constituents of Prunus domestica. Journal of the Science of Food and Agriculture, v.10, n.1, p.63-68, 1959.

64 TAKAHASHI, H.; KASHIMURAA, M.; KOISOB, H.; KUDAA, T.; KIMURA, B. Use of ferulic acid as a novel candidate of growth inhibiting agent against Listeria monocytogenes in ready-to-eat food. Food Control, v.33, n.1, p.244-248, 2013.

$65 \mathrm{TEH}, \mathrm{S} . \mathrm{S} ; \mathrm{BIRCH}$, E.J. Effect of ultrasonic treatment on the polyphenol content and antioxidant capacity of extract from defatted hemp, flax and canola seed cakes. Ultrasonics Sonochemistry, v. 21, n.1, p. 346-353, 2014.

66 UPADHYAY, B.; SINGH, K.P.; KUMAR, A. Ethno-medicinal, phytochemical and antimicrobial studies of Euphorbia Tirucalli L. Journal of Phytology, v.2, n.4, p.65-77, 2010. 
67 VARRICCHIO, M.C.B.N.; ORMELEZ, E.G.; SILVA, S.D.A; SATO, A.; HENRIQUES, A.B.; LAGE, C.L.S. Euphorbia tirucalli $L$.: Análise qualitativa do desenvolvimento vegetal durante o cultivo in vitro. Revista de Biologia e Farmácia, v.3, n.1, p.53-65, 2008

68 WACZUK, E.P.; KAMDEM, J.P.; ABOLAJI, A.O.; MEINERZ, D.F.; BUENO, D.C.; GONZAGA, T.K.S.N.; DOROW, T.S.C.; BOLIGON, A.A.; ATHAYDE, M.L.; ROCHA, J.B.T.; ÁVILA. D.S. Euphorbia tirucalli aqueous extract induces cytotoxicity, genotoxicity and changes in antioxidant gene expression in human leukocytes. Toxicology Research, v. 4, p. 739-748, 2015.

69 WANG, S.; MELNYK, J.P.; TSAO, R.; MARCONE, M.F. How natural dietary antioxidant in fruits, vegetables and legumes promote a vascular health. Food Research International, v.44, n.1, p.14-22, 2011.

70 WOOTTON-BEARD, P.C.; RYAN, L. Improving public health?: The role of antioxidant-rich fruit and vegetables beverages. Food Research International, v.44, n.10, p.3135-3148, 2011.

\section{AGRADECIMENTOS}

À Universidade Federal do Piauí (UFPI) por meio do Programa de Pós-Graduação em Biotecnologia; Ao Instituto Federal de Educação, Ciência e Tecnologia do Piauí (IFPI) pela estrutura laboratorial para as análises da atividade antioxidante; Ao Instituto Butantan pelas análises de viabilidade celular e atividade antiparasitária; À Universidade Federal do Rio de Janeiro (UFRJ) pela estrutura laboratorial para manuseio das amostras. À Profa. Dra. Ivanilza Moreira de Andrade do Laboratório de Taxonomia da Universidade Federal do Piauí, campus de Parnaíba, pela identificação da espécies. Ao CNPq pela concessão de apoio financeiro por meio do projeto de pesquisa aprovado pelo autor RAT no edital Universal CNPq (Proc. № 474144/2012-7) e à CAPES pela concessão de bolsa de mestrado ao primeiro autor deste trabalho (PHHVJ). 